\title{
Effect of viral infection on brain functions and Psychological Impact of the COVID-19 on our thinking and mood
}

\author{
Javeria Maqbool ${ }^{1}$, Azhar Rasul ${ }^{2}$, Javed Iqbal ${ }^{2}$, Haseeb Anwar ${ }^{2}$, Ali Imran², Rabia Akram², \\ Faiqa Sajid ${ }^{1}$, Atia Iftikhar², Tehreem Asghar ${ }^{2}$, Muhammad Asrar ${ }^{2}$, Tao Sun ${ }^{2}$, and Ghulam \\ Hussain $^{2}$ \\ ${ }^{1}$ Government College University Faisalabad \\ ${ }^{2}$ Affiliation not available
}

August 8, 2021

\begin{abstract}
Background: Viral infections such as measles virus (MV), herpes virus, and human immunodeficiency virus (HIV) can lead to transient or permanent neurological or psychiatric dysfunction. However, respiratory system affecting viruses have appeared as an unbeatable challenge to the modern world. They include the human respiratory syncytial virus (hRSV), the influenza virus (IV), and the coronavirus (CoV). They cause acute respiratory infections mainly children under 5 years old and also the elderly. The most frequent clinical manifestations are febrile or afebrile seizures, status epilepticus, encephalopathies, and encephalitis. Objective: The objective of this review is to assess the effect of COVID-19 on our mood and thinking during this pandemic. Method: We reviewed the literature using different databases e.g., Google Scholar, PubMed, and Science direct etc. Results: Viral Infections badly affect the nervous system functions and ultimate can lead to the onset of neurological and psychological illnesses. Conclusion: COVID-19 is somehow causing depression, anxiety, panic attacks, and stress. As a consequence, social distancing has increased that has ultimately modified our thinking style, mood and has lead to the psychological, emotional and behavioral changes. Review Criteria We reviewed the literature using different databases e.g., Google Scholar, PubMed, etc. from 1997 to 2021 without language limitations. Message for the clinic It is clear that COVID-19 causes cardiac, respiratory, renal, and gastrointestinal dysfunctions and has also a direct effect on brain functioning resulting in psychological and behavioral changes. Along with other dysfunctions, it has severely affected the living style of people and brought depression, anxiety, panic attacks, loneliness, and self-deprecation. It is highly recommended that while treating such patients, all these aspects should be kept in mind. Hence, not only medication can ameliorate the side impacts of this infection but counseling is another tool to bring positive impact in those respondents.
\end{abstract}

\section{Hosted file}

Maqbool_et_al.,Effect_of_viral_infection_on_brain_functions_and_Psychological_Impact_of_the_COVID-19_on available at https://authorea.com/users/429609/articles/533293-effect-of-viral-infectionon-brain-functions-and-psychological-impact-of-the-covid-19-on-our-thinking-and-mood

\section{Hosted file}

Maqbool et al.,Effect of viral infection on brain functions and Psychological Impact of the CoVID-19 on available at https://authorea.com/users/429609/articles/533293-effect-of-viral-infectionon-brain-functions-and-psychological-impact-of-the-covid-19-on-our-thinking-and-mood 